\title{
Habilidades para Letramento Digital: Um Estudo Comparativo Entre Alunos de Curso Oferecido nas Modalidades à Distância e Presencial
}

\author{
Juliana Saboia ${ }^{1}$, Magda Lorenz Granville ${ }^{2}$, Renata Gianotti ${ }^{3}$, \\ Sandra Andrea Assumpção Maria ${ }^{4}$, Patrícia Alejandra Behar ${ }^{4}$ \\ ${ }^{1}$ Cesuca - Faculdade Inedi \\ Cachoeirinha, RS - Brasil \\ ${ }^{2}$ Universidade Federal de Ciências da Saúde de Porto Alegre (UFCSPA) \\ Porto Alegre, RS - Brasil \\ ${ }^{3}$ Universidade do Vale do Rio dos Sinos (UNISINOS) \\ São Leopoldo, RS - Brasil \\ ${ }^{4}$ Universidade Federal do Rio Grande do Sul (UFRGS) \\ Porto Alegre, RS - Brasil \\ jusaboiallive.com, \{mlorenzgranville, renatagianotti, \\ sandradeia\}@gmail.com, patricia.behareufrgs.br
}

\begin{abstract}
The digital inclusion can be built in different ways, being one of them throughout digital literacy. Data shows that in Brazil, there still exists an expressive distance between social classes in regards to computing and Internet access, turning hard the digital inclusion of poorer classes. Understanding that the digital literacy is a fundamental aspect for the advancement of students' education and digital inclusion, this paper evaluates the abilities and competences linked to digital literacy of regular and distance learning students of technological course, through a survey of 74 students from a University in the south of Brazil.
\end{abstract}

Resumo. A inclusão digital pode ser construida de diversas formas, sendo uma delas por meio do letramento digital. Dados demonstram que no Brasil ainda existe uma distância expressiva entre as classes sociais no que tange o acesso a computadores e à Internet, dificultando a inclusão digital das classes menos favorecidas. Entendendo o letramento digital como fundamental para o avanço na educação e na inclusão digital dos alunos, este artigo avalia as habilidades e competências vinculadas ao letramento digital de alunos de Cursos Tecnológicos de Formação Superior oferecidos por Instituição do Sul do Brasil, nas modalidades presencial e à distância (EaD), observadas por meio de survey realizada com 74 alunos.

\section{Introdução}

É inegável o desenvolvimento de novas tecnologias de informação e comunicação e é indiscutível que conteúdos digitais educacionais estão sendo intensamente utilizados como recursos pedagógicos para contribuir com a educação de pessoas. Num mundo onde as habilidades associadas com inovação e utilização de tecnologias digitais são cada vez mais relevantes, falar em democratização do conhecimento significa romper com as fronteiras e restrições que impedem o acesso às informações do ciberespaço, 
independente de origem social ou de renda. É possível que por esse caminho esteja ocorrendo efetivamente uma revolução visando à distribuição democrática do conhecimento. No entanto, Araújo (2007) diz que o acesso ao letramento digital tem sido disponibilizado em maior parte aos grupos sociais privilegiados, provocando a exclusão digital.

De fato, a facilidade de acesso ao conhecimento, por meio das diferentes tecnologias, permitiu repensar sua utilização para potencializar o acesso à educação formal. Pesquisas têm mostrado, porém, que o acesso a recursos de tecnologia de informação e comunicação não acontece em todos os lares brasileiros. Em 2013, uma pesquisa realizada pelo Centro de Estudos sobre as Tecnologias da Informação e da Comunicação (CETIC) mostrou que $46 \%$ dos lares brasileiros possuem computador, sendo que nesses, na população classificada como classe $\mathrm{C}$ o percentual representa $44 \%$, e na classe D, apenas $9 \%$. Em relação ao uso da Internet, os dados mostram que $97 \%$ dos que integram a classe A utilizam esses recursos, enquanto que nas classes $\mathrm{C}$ e $\mathrm{D}, \mathrm{o}$ acesso é de $36 \%$ e $6 \%$, respectivamente.

Considerando a importância do uso da tecnologia como recurso de inclusão social e a escola como parte integrante desse processo, confirma-se a existência de uma lacuna de acesso à tecnologia existente no País. Tal lacuna se caracteriza como uma restrição ao domínio das competências de letramento digital dos alunos e do planejamento de atividades que implicam no uso destas competências.

Este artigo tem como objetivo apresentar os resultados da avaliação comparativa das habilidades vinculadas ao letramento digital de alunos de cursos superiores de tecnologia oferecidos nas modalidades presencial e educação à distância (EaD), a partir do mapeamento das habilidades e competências identificadas no letramento digital. $\mathrm{O}$ artigo está estruturado em cinco seções. Na Seção 2 o referencial teórico é apresentado. A metodologia está descrita na Seção 3, enquanto a análise descritiva de resultados e as considerações finais estão apresentadas nas Seções 4 e 5, respectivamente.

\section{Referencial Teórico}

\subsection{Inclusão Digital}

O domínio digital é fator indissociável da democratização da tecnologia. Sem a tecnologia de informação é praticamente impossível que um grande número de pessoas tenha acesso ao conhecimento. Araújo, Araújo e Lima (2010) apontam que, se no início dos anos 2000, questões como infraestrutura e acesso eram tidas como emergenciais para o processo de democratização do uso das tecnologias da informação e comunicação (TIC), atualmente essa questão é tratada como fator imprescindível da inclusão digital.

A pesquisa realizada pelo CETIC (2013) evidencia diferenças relativas à inclusão digital não só entre as classes sociais, mas também em relação a regiões brasileiras. Os resultados observados nos estados do Sul e Sudeste mostram maior acesso de indivíduos ao computador e à Internet em relações aos estados do Norte e Nordeste. Em relação às classes sociais, a pesquisa monstrou que o percentual de pessoas da classe A que nunca usaram a Internet é de 5\%, e de $80 \%$ nas classes D e E. Isso possibilita entender a exclusão digital das camadas menos favorecidas, uma vez que não possuem possibilidades e condições de desenvolver práticas digitais simples, como escrever um e-mail, acessar redes sociais e realizar cursos on-line. 
Quando se fala em inclusão digital, é necessário esclarecer que se trata de permitir que pessoas não somente tenham acesso às tecnologias, mas que se tornem agentes capazes de reconhecer o potencial crítico e comunicacional que as tecnologias trazem consigo. A utilização de recursos educacionais que contemplam o ciberespaço como fonte de contínua formação merece atenção especial, no sentido de contemplar as competências individuais de seus usuários. Isso possibilitará que os "percursos individualizados", de acordo com Alava (2002), sejam percorridos de forma profícua. Desta forma, conforme Buzato (2008), inclusão digital é a "possibilidade de subversão das relações de poder e das formas de opressão que se nutrem e se perpetuam por meio da homogeneização, da padronização, da imposição de necessidades estabelecidas por alguns para todos e do fechamento dos 'significados' das novas tecnologias de informação e comunicação (TIC) em função dessas necessidades".

A diversidade tecnológica possibilita que pessoal tenham acesso a grandes quantidades de informação e em variada abrangência de profundidade científica e empírica. Por isso, quanto maior a necessidade de apropriação de informações mais relevantes se torna o domínio das tecnologias para evitar a caracterização de nova categoria de analfabetos funcionais: o analfabeto digital.

Considerando que o domínio tecnológico também influencia a capacidade de analisar criticamente a informação disponibilizada, o fato de um indivíduo ter acesso às tecnologias diversas não prova que possua a competência para analisar e refletir criticamente conteúdos propostos. De acordo com Amiel e Amaral (2013), "há crescente evidência da inexistência de um grupo homogêneo de alunos no que diz respeito aos conhecimentos sobre o uso de novas mídias", evidenciando que a utilização de mídias não comprova competências ou habilidades midiáticas, além de que, diante desse uso, identificam-se "competências e preferências variadas", citadas pelos autores.

Conforme aponta Buzato (2009), quando se entende a inclusão digital como "dependente do uso, transformação e aplicação das tecnologias da comunicação e informação (TIC), se requer muito mais do que acesso e capacitação básica". Desta forma, surge a necessidade e oportunidade de pensar-se em letramento(s) digital(is).

\subsection{Letramento Digital e Competências}

Diferentes formatos de textos ampliam a capacidade de leitura e, conforme Ribeiro (2009), "não há limites para o letramento, uma vez que sempre surgirão novas formas de escrever, novos gêneros de texto, e suportes de leitura. A Internet e as máquinas digitais estão entre as opções mais recentes". Conforme Behar et al. (2013) "novos tipos de práticas baseadas na informática e na Internet estão surgindo e com eles diferentes tipos de letramento".

Como aponta Araújo (2007), o letramento está vinculado à capacidade do indivíduo em aplicar, nas diversas situações sociais, o conhecimento do código referenciado, com a desenvoltura das modalidades escrita e oral da língua. Por outro lado, Buzato (2008) informa que letramento digital não é apenas a transposição de letramentos convencionais para novas condições 'de mediação' e sim “configura redes complexas de letramentos (práticas sociais) que se apoiam, entrelaçam, contestam e modificam mútua e continuamente com a influência das TIC, e que o fazem de formas diversas conforme os contextos culturais e os ambientes situacionais diferentes". 
Behar et al. (2013) diz que a expressão "letramento digital" abrange um conjunto de "letramentos originados tanto dos aspectos tecnológicos quanto do cenário social". Colaborando com essa visão, Freitas (2010) aponta que "ser letrado digital inclui, além do conhecimento funcional sobre o uso da tecnologia, o conhecimento crítico desse uso". Para se tornar digitalmente letrado o indivíduo apreende e utiliza um novo tipo de discurso, semelhante ao processo de aprendizado de outro idioma.

Conceituado o letramento digital, é necessário compreender as competências que o compõem. Competência é, segundo Zabala e Arnau (2011), apud Behar, Bernardi e Maria (2013), "a capacidade ou a habilidade de realizar tarefas ou atuar frente a situações diversas de forma eficaz em um determinado contexto". Ainda, para sua construção é necessário mobilizar conhecimento, habilidade e atitude, "ao mesmo tempo e de forma inter-relacionada". As competências que compõem o letramento digital são: computacional, comunicacional, informacional e multimídia (BEAHR et al., 2013). A Tabela 1 apresenta tais competências e habilidades.

Tabela 1: Quadro de competências do letramento digital e suas habilidades e conhecimentos. Fonte: Adaptado de Behar et al. (2013)

\begin{tabular}{|c|c|}
\hline CONHECIMENTOS & HABILIDADES \\
\hline \multicolumn{2}{|c|}{ Competência Computacional: relacionada aos conhecimentos básicos para o uso do computador. } \\
\hline $\begin{array}{l}\text { - Conhecer os softwares e(programas e ferramentas) } \\
\text { disponíveis } \\
\text { - Saber instalar programas e reconhecer aqueles que são } \\
\text { desnecessários e tornam lentos o computador } \\
\text { - Conhecer os elementos básicos do computador e suas } \\
\text { funções } \\
\text { - } \text { - Conhecer a terminologia básica do sistema operacional } \\
\text { diferentes suportes (pen-drives, disco rígido, HD } \\
\text { externo, pastas, etc.) }\end{array}$ & $\begin{array}{l}\text { - } \text { - Saber operar o básico de uma ferramenta } \\
\text { - } \text { Saber operar os recursos multimídia } \\
\text { - } \text { Saber utilizar as ferramentas básicas do sistema operacional: } \\
\text { explorar discos, copiar, executar programa, etc. } \\
\text { - Utilizar editor de textos para redigir documentos, armazená-los e } \\
\text { imprimi-los } \\
\text { - Utilizar editores gráficos para fazer desenhos, gráficos simples, } \\
\text { armazenar e imprimir o trabalho } \\
\text { - Utilizar ferramentas de apresentação para organizar e expor a } \\
\text { informação }\end{array}$ \\
\hline \multicolumn{2}{|c|}{ Competência Comunicacional: Relacionada à expressão oral, gestual e escrita. } \\
\hline $\begin{array}{l}\text { - Conhecer as diferentes Redes Sociais } \\
\text { - Conhecer a etiqueta e as diferentes formas de escrita nas } \\
\text { várias ferramentas disponíveis na internet, como bate- } \\
\text { papo, e-mail, etc. } \\
\text { - Conhecer as formas de escrita específicas para cada } \\
\text { ferramenta, como bate-papo, e-mail, fórum, etc. }\end{array}$ & $\begin{array}{l}\text { - Saber utilizar as redes para contatar outras pessoas, debater com } \\
\text { elas e ajudá-las e pedir ajuda } \\
\text { - } \text { Digitar razoavelmente rápido } \\
\text { - Selecionar o conteúdo exposto nas redes sociais } \\
\text { - } \\
\text { Fazer contribuições relevantes }\end{array}$ \\
\hline \multicolumn{2}{|c|}{ Competência Multimídia: Relacionada à utilização de diferentes tipos de mídia. } \\
\hline $\begin{array}{l}\text { - Conhecer os diversos tipos de mídia } \\
\text { - Saber preparar conteúdos atrativos } \\
\text { - Ter conhecimento para escolher o conteúdo dos jogos } \\
\text { pedagógicos } \\
\text { - Conhecer hipertextos e hipermídia } \\
\text { - Saber elaborar transparências e apresentações multimídia } \\
\text { - Ter conhecimentos de design e elaboração de páginas } \\
\text { web } \\
\text { - Saber realizar a manutenção de um espaço web em um } \\
\text { servidor }\end{array}$ & $\begin{array}{l}\text { - } \text { Combinar visualmente diferentes tipos de mídias } \\
\text { - } \text { Criar materiais atrativos e de acordo com a faixa de idade de cada } \\
\text { um } \\
\text { - } \text { Produzir materiais que sejam visualmente agradáveis } \\
\text { - } \text { Testar as mídias e estar preparado para alguns contratempos } \\
\text { - } \\
\text { Ter habilidades de leitura e compreensão em um ambiente de } \\
\text { hipertexto dinâmicos e não sequencial } \\
\text { - } \\
\text { Saber realizar tratamento de imagem e som: editores gráficos, uso } \\
\text { de escâner, gravação de som, vídeo digital, etc. }\end{array}$ \\
\hline \multicolumn{2}{|c|}{ Competência Informacional: Relacionada à busca, avaliação e utilização de informações. } \\
\hline $\begin{array}{l}\text { - Conhecer diferentes sites de busca } \\
\text { - Conhecer e aprender a utilizar sites de download para } \\
\text { programas, livros e filmes } \\
\text { - Ter claro o que é informação e o que é conhecimento } \\
\text { - Fazer juízos de valor informados e fundamentados sobre } \\
\text { a informação obtida por meio de tecnologias digitais }\end{array}$ & $\begin{array}{l}\text { - } \text { Avaliar diferentes fontes } \\
\text { - Relacionar o conteúdo trabalhado com informações adicionadas } \\
\text { coletadas } \\
\text { - Comparar e selecionar as informações relevantes } \\
\text { - Desenvolver técnicas e instrumentos para a busca, exame e } \\
\text { seleção de informações na internet. } \\
\text { - Construir informações confiáveis a partir de diversas fontes }\end{array}$ \\
\hline
\end{tabular}

Gilster (1997, apud Freitas, 2010) aponta a necessidade de proficiência em quatro competências para o letramento digital: capacidade de realizar a avaliação crítica de conteúdo, sendo a capacidade de julgar o que é encontrado na rede; capacidade de ler 
utilizando o modelo não-linear ou hipertextual; capacidade de associar as informações de diferentes fontes e; capacidade de realizar buscas para lidar com o biblioteca virtual.

$\mathrm{O}$ desenvolvimento do artigo considerou, no que tange às competências e suas habilidades relacionadas, a estrutura proposta Beahr et al. (2013).

\section{Metodologia}

O delineamento da pesquisa, segundo Saccol et al. (2012), é composto por três elementos essenciais: o paradigma da pesquisa, sua classificação quanto à finalidade e o método de pesquisa a ser utilizado. Em relação ao paradigma, a pesquisa apresenta caráter quantitativo, adotando instrumentos estruturados e pressupondo a quantificação e a análise dos dados coletados por meio de recursos estatísticos. Em relação à abordagem utilizada, a pesquisa foi classificada como descritiva uma vez que sua finalidade é descrever situações, comportamentos e conhecimentos, de forma a mapear o fenômeno no contexto pesquisado. O método utilizado foi o de pesquisa por levantamento, ou Survey, que, segundo Gil (2010, apud SACCOL, 2012), se caracteriza pela interrogação direta aos indivíduos cujo comportamento, opinião ou características se desejam conhecer.

Alunos de cursos tecnológicos de formação superior em áreas de gestão, oferecidos nas modalidades presencial e à distância, são a população alvo deste estudo. De acordo com Roesch (1999), "dependendo de fatores como tamanho da população, custo da pesquisa, capacidade de processamento dos dados ou os objetivos e finalidades da pesquisa, é recomendável extrair uma parcela da população para investigar". Para o desenvolvimento do estudo foi estabelecida uma amostra por conveniência com alunos matriculados em diferentes níveis dos cursos nas duas modalidades.

O questionário, elaborado com perguntas fundamentadas nas competências estudadas em Behar et al. (2013), Tabela 1, foi aplicado entre os dias 15 de maio a 05 de junho de 2014, em sala de aula e por meio do ambiente virtual de aprendizagem. Participaram do estudo 74 alunos, dos quais 44 do curso presencial e 30 do curso EaD.

Os indicadores envolveram perguntas fechadas, alguns associados a uma escala nominal e outros vinculados a escala Likert. Foram apresentados grupos de perguntas relacionados a: acesso a redes sociais, ferramentas e softwares de apoio ao processo de ensino, e habilidade em utilizar os recursos computacionais. Para a análise dos dados, foram determinadas frequências de ocorrência, porcentagens e descritores de resultados comparativos nas diferentes amostras, sendo utilizada uma planilha de dados estatísticos.

\section{Análise dos resultados}

Após a aplicação e validação do questionário, os dados e informações foram tabulados descrevendo inicialmente o perfil dos participantes da amostra. A seguir foram discutidas as habilidades vinculadas às competências estabelecidas em nome do letramento digital.

\subsection{Características da amostra}

Todos os respondentes são alunos de cursos tecnológicos de formação superior na área de gestão. A amostra estudada mostrou que $50 \%$ dos respondentes são do sexo masculino e 79\% tem idade entre 17 e 34 anos. As faixas etárias foram assim distribuídas para adequar às atuais gerações enumeradas na Sociologia e no Marketing. 
Nos últimos 70 anos, cinco gerações marcaram época na sociedade contemporânea, mudando valores e a forma da sociedade pensar e se comportar. Atualmente, elas convivem e se "reinventam" a partir de um novo paradigma: a tecnologia (Revista IHU, maio/2011). De acordo com Oliveira (2009), os nascidos entre 1960 e 1980 são caracterizados como "geração X". Os nascidos entre 1980 e 1990 formam a "geração Y" e os nascidos após 1990 compõem a "geração Z", também conhecidos como nativos digitais.

O estudo considerou as faixas de renda estabelecidas pela Fundação Getúlio Vargas em 2011, a qual considera a renda média de famílias compostas por quatro integrantes, a saber: Classes E e D, renda até $\mathrm{R} \$ 1.734,00$; Classe $\mathrm{C}$, renda entre $\mathrm{R} \$$ 1.734,00 e R \$ 7.475,00; Classes A e B, com renda superior a $\mathrm{R} \$ 7.475,00$. A maioria dos respondentes pertence à Classe $\mathrm{C}$ e 65 respondentes exercem trabalho remunerado.

O perfil em termos de acesso evidenciou as seguintes características: 72 dos respondentes possuem computador ou notebook em seu domicílio para uso particular; cada domicilio possui em média 1,8 computadores ou notebooks; 69 respondentes (i.e., $93,2 \%$ ) afirmaram possuir acesso domiciliar à Internet.

\subsection{Análise comparativa das Habilidades e Conhecimentos}

Questionados sobre os quesitos que compõem as habilidades e conhecimentos vinculados às competências transversais do letramento digital, dividimos os resultados obtidos entre elas.

\subsubsection{Competência Comunicacional}

Os alunos foram questionados sobre frequência de uso de algumas redes. Foram obtidas frequências de respostas e analisadas as medianas destas frequências de uso. Observouse que o Facebook tem a preferência dos respondentes, com mais de $70 \%$ dos estudantes conectados diariamente. Redes sociais que serviriam de apoio ao processo de aprendizagem, como YouTube e SlideShare, têm uso completamente diferente. O exame da mediana contribuiu na análise, uma vez que foi constatado que o uso das redes sociais (e.g., SlideShare) com ampla participação no material de apoio à aprendizagem apresenta mais de 50\% dos respondentes não usuários.

O Google+ é mais utilizado pelos alunos $\mathrm{EaD}$, sendo que $50 \%$ destes alunos acessam mais de uma vez ao mês. Para o YouTube, os resultados foram semelhantes tanto para alunos EaD como para presenciais, ficando a mediana do acesso em 3, ou seja, acessa nos finais de semana. Além destas redes, foi citado o aplicativo WhatsApp, para o qual $23 \%$ dos alunos EaD afirmaram estar sempre conectados, assim como $16 \%$ dos alunos presenciais.

\subsubsection{Competência Computacional}

Referente aos softwares e sites mais usuais no processo de ensino-aprendizagem, foram pesquisados editores de texto, planilhas de dados, softwares de apresentação (PowerPoint e Prezi), softwares para elaborar mapas conceituais, sites de pesquisa de conteúdo, programas de downloads de filmes, sites de pesquisas sobre artigos científicos e editores de filmes.

Referente aos editores de texto, tanto alunos $\mathrm{EaD}$ como presenciais afirmaram possuir algum conhecimento. Os alunos $\mathrm{EaD}$ afirmam ter conhecimento básico ou 
maior, sendo que $83 \%$ dos alunos EaD afirmam ter conhecimento intermediário ou avançado, enquanto entre os alunos presenciais 7\% afirmaram ter conhecimentos mínimos, e somente $63 \%$ ter conhecimentos intermediários e avançados.

No que se refere aos conhecimentos relativos às planilhas de dados e softwares de apresentações, não foram observadas diferenças percebíveis entre os alunos EaD e presenciais: $5 \%$ dos alunos presenciais responderam não ter conhecimento nenhum, enquanto nenhum aluno EaD deu esta resposta. Por outro lado, aproximadamente $32 \%$ dos alunos presenciais afirmaram ter conhecimentos intermediário ou avançado contra aproximadamente $65 \%$ dos alunos $\mathrm{EaD}$. As ferramentas mais atuais como o Prezi e mapas conceituais apresentaram baixo nível de conhecimento, em qualquer uma das modalidades de ensino. Apenas 3\% dos alunos EaD manifestaram ter conhecimentos avançados nestas duas ferramentas.

Em relação a sites de busca, tanto os alunos presenciais quanto EaD afirmaram possuir habilidades intermediárias e avançadas. Já sobre sites de download de filmes e sites de busca de artigos científicos, os alunos de ambas as modalidades afirmaram possuir, na grande maioria, algum conhecimento. No entanto, poucos afirmam possuir conhecimentos avançados nestes tipos de sites. Por fim, referente a editores de filmes, somente $2 \%$ dos alunos presenciais afirmaram ter conhecimentos avançados versus nenhum aluno $\mathrm{EaD}$. Em torno de $45 \%$ de ambas as modalidades afirmaram não ter conhecimento destas ferramentas.

Analisando as medianas alocadas no gráfico da Figura 1, confirma-se que há maior habilidade dos alunos EaD em planilhas de dados, softwares de apresentação e buscas de artigos científicos em sites especializados em comparação aos alunos presenciais. Nas demais ferramentas, a habilidade é aproximadamente a mesma.

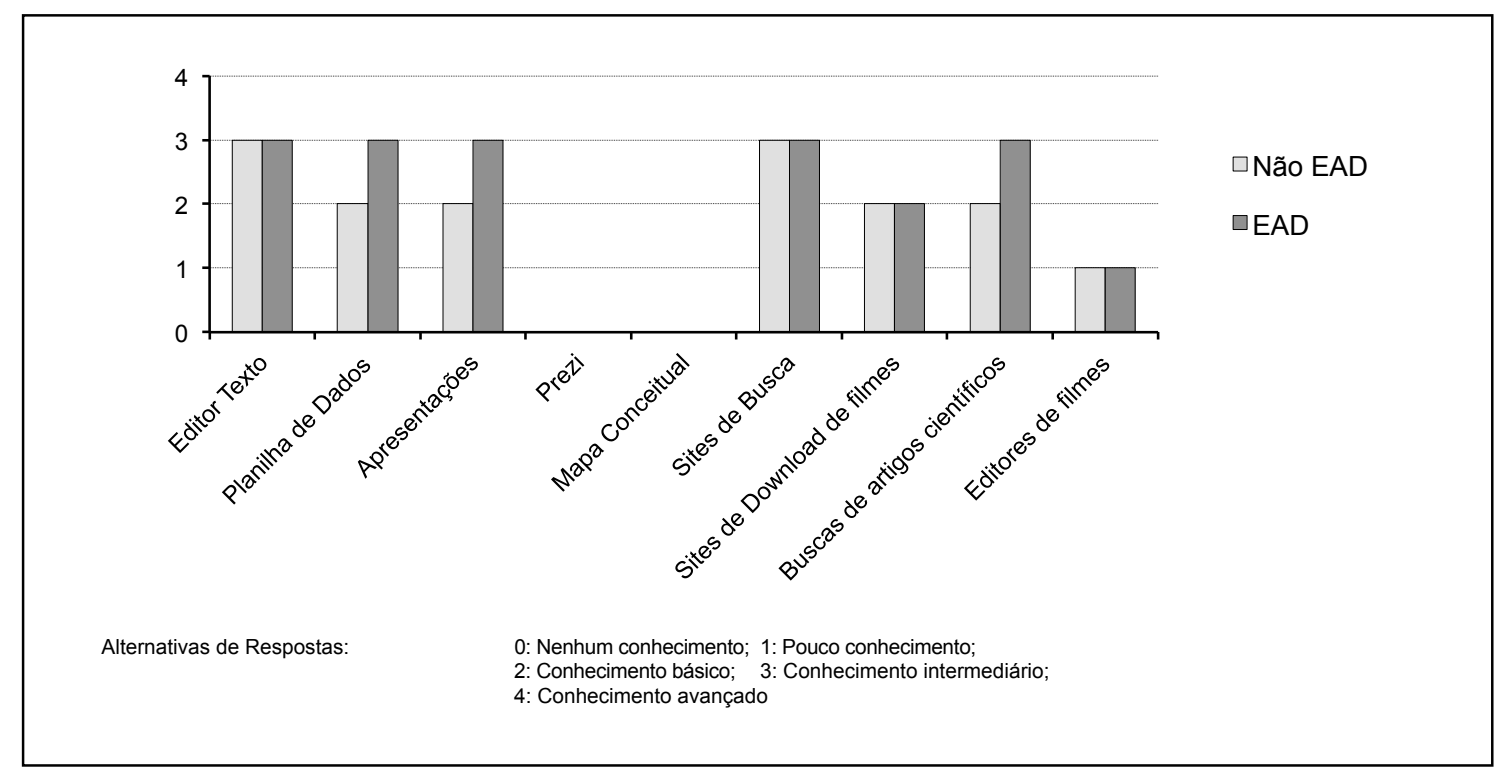

Figura 1: Comparativo das medianas do uso de ferramentas computacionais Fonte: Elaborado pelas autoras com base na pesquisa.

\subsubsection{Competência Informacional}

Analisando o nível de conhecimento e habilidades de uso dos recursos computacionais, foram feitas seis perguntas as quais os alunos deveriam responder se tinham 
conhecimento básico, intermediário, avançado ou se não tinham conhecimento algum. A tabela 2 apresenta o resumo dos resultados coletados.

Tabela 2: Nível de conhecimento e habilidades do uso dos recursos computacionais. Fonte: Elaborado pelas autoras com base na pesquisa.

\begin{tabular}{|c|c|c|c|c|c|c|}
\hline \multicolumn{2}{|c|}{ Conhecimento: } & Nenhum & Básico & Intermediário & Avançado & TOTAL \\
\hline \multirow{2}{*}{$\begin{array}{l}\text { a) Conhece os termos básicos sobre computador (arquivos, } \\
\text { pastas, programas, aplicativos, programas, etc.)? }\end{array}$} & Não EAD & $0 \%$ & $27 \%$ & $34 \%$ & $39 \%$ & 44 \\
\hline & EAD & $0 \%$ & $23 \%$ & $43 \%$ & $33 \%$ & 30 \\
\hline \multirow{2}{*}{$\begin{array}{l}\text { b) Conhece os elementos básicos de um computador e } \\
\text { suas funções? }\end{array}$} & Não EAD & $0 \%$ & $32 \%$ & $41 \%$ & $27 \%$ & 44 \\
\hline & EAD & $0 \%$ & $40 \%$ & $33 \%$ & $27 \%$ & 30 \\
\hline \multirow{2}{*}{$\begin{array}{l}\text { c) Sabe salvar e recuperar informações e arquivos no } \\
\text { computador ou em diferentes suportes (pendrive, hd } \\
\text { externo, disco rígido, pastas, etc.)? }\end{array}$} & Não EAD & $5 \%$ & $18 \%$ & $39 \%$ & $39 \%$ & 44 \\
\hline & EAD & $0 \%$ & $17 \%$ & $63 \%$ & $20 \%$ & 30 \\
\hline \multirow{2}{*}{$\begin{array}{l}\text { d) Utiliza atalhos, que facilitam a realização de tarefas } \\
\text { (seleção de texto, copiar e colar textos, etc). }\end{array}$} & Não EAD & $0 \%$ & $14 \%$ & $45 \%$ & $41 \%$ & 44 \\
\hline & EAD & $3 \%$ & $10 \%$ & $53 \%$ & $33 \%$ & 30 \\
\hline \multirow{2}{*}{ e) Sabe instalar programas? } & Não EAD & $11 \%$ & $25 \%$ & $39 \%$ & $25 \%$ & 44 \\
\hline & EAD & $7 \%$ & $27 \%$ & $40 \%$ & $27 \%$ & 30 \\
\hline \multirow{2}{*}{$\begin{array}{l}\text { f) Sabe reconhecer quando um programa instalado é } \\
\text { desnecessário e/ou que deixa o computador lento? }\end{array}$} & Não EAD & $16 \%$ & $41 \%$ & $27 \%$ & $16 \%$ & 44 \\
\hline & EAD & $23 \%$ & $47 \%$ & $13 \%$ & $17 \%$ & 30 \\
\hline
\end{tabular}

Em relação ao domínio dos termos básicos sobre computador, todos os respondentes afirmaram possuir algum conhecimento, sendo que $76 \%$ dos alunos $\mathrm{EaD}$ afirmaram possuir conhecimentos intermediários e avançados, contra $73 \%$ dos alunos de cursos presenciais, ou seja, resultados bastante semelhantes.

Sobre conhecer os elementos básicos de um computador e suas funções, as respostas apresentaram pequenas modificações. Assim, obteve-se que nenhum respondente afirmou não possuir conhecimentos e $73 \%$ dos alunos de ambas as modalidades possuíam conhecimentos básicos ou intermediários.

$\mathrm{O}$ indicador relacionado à capacidade de salvar e recuperar informações e arquivos no computador mostrou que $5 \%$ dos respondentes na modalidade presencial reconhecem não ter nenhum conhecimento. Porém, ainda junto aos alunos presenciais, se observou um maior número de respondentes com conhecimentos avançados (39\%), em contraponto aos respondentes $\mathrm{EaD}$ em que maior parte $(63 \%)$ afirmou possuir conhecimentos intermediários.

Em relação ao uso de atalhos que facilitam a realização de tarefas, $86 \%$ dos alunos das duas modalidades responderam ter conhecimento intermediário ou avançado, sendo que $41 \%$ dos alunos presenciais e $33 \%$ dos alunos EaD manifestaram possuir conhecimentos avançados.

Quanto à capacidade de instalar programas, os resultados mostraram que: $11 \%$ dos alunos presenciais e $7 \%$ dos alunos EaD afirmaram não ter conhecimentos, $25 \%$ dos presenciais e $27 \%$ dos EaD afirmaram possuir conhecimentos avançados e aproximadamente $39 \%$ de cada grupo afirmaram ter conhecimentos intermediários.

Ao final, sobre a capacidade de reconhecer a utilidade do programa instalado ou se estes interferem negativamente no desempenho do equipamento, as respostas produzidas indicaram que $23 \%$ dos alunos EaD não têm esse conhecimento contra $16 \%$ dos alunos presenciais, mostrando que os alunos EaD têm menos habilidade nessa questão. Para reforçar essa condição, verificou-se que $30 \%$ dos alunos $\mathrm{EaD}$ têm conhecimentos intermediários ou avançados contra $43 \%$ dos alunos presenciais. 
Analisando as medianas das respostas entre os dois grupos, não foi possível perceber diferença entre estes, ficando as medianas nas cinco primeiras perguntas com o valor de dois, ou seja, conhecimento intermediário. Somente na última pergunta, sobre reconhecer quando um programa instalado é desnecessário e/ou que deixa o computador lento, a mediana se apresentou com o valor um, ou seja, conhecimento básico.

Foi feita um verificação sobre se os alunos possuíam blogs e sites próprios e se sabiam fazer manutenções de sites. Somente 4 alunos $\mathrm{EaD}$ afirmaram ter blogs e 7 respondentes afirmaram ter sites próprios, sendo 4 destes alunos presenciais e $3 \mathrm{EaD}$. Em relação a elaboração e manutenção de sites, 8 respondentes afirmaram saber elaborá-los, sendo $6 \mathrm{EaD}$. Em relação à manutenção, 6 alunos responderam saber fazer manutenções, sendo $4 \mathrm{EaD}$.

\section{Considerações Finais}

As informações coletadas por meio de questionários apresentam como limitação a influência da percepção dos respondentes no resultado a ser obtido nas respostas. Em outras palavras, o recurso utilizado gerou dados referentes à percepção que os indivíduos têm sobre si mesmos.

A condição de competência do letramento digital demonstra o quanto é essencial para o desenvolvimento do aluno a sua inclusão digital social. Por meio do estudo apresentado, foi possível compreender a complexidade e a importância dessa competência para a formação de um aluno crítico e completo.

O objetivo geral do estudo foi realizar a avaliação das habilidades vinculadas ao letramento digital em alunos de cursos tecnológicos comparando as modalidades EaD e presencial. Tal objetivo foi alcançado através da coleta e análise dos dados, onde foi possível auferir que há diferenças entre os grupos de alunos. No entanto, estas diferenças, ao contrário do que se imagina empiricamente, não são significativamente percebidas nas habilidades questionadas aos alunos respondentes.

Como objetivos específicos, a pesquisa propôs a avaliação das habilidades e conhecimentos das competências que compõem o letramento digital. Na competência comunicacional foi possível verificar que a maioria dos alunos está bastante conectada ao Facebook. No entanto, em outras redes isto não é tão evidente. Em relação a competência computacional, os dados mostraram que os alunos EaD apresentam maior habilidade em algumas ferramentas em relação aos alunos presenciais, destacando-se os resultados referentes as planilhas de dados, softwares de apresentações e buscas em sites de artigos científicos. Já, com relação a competência informacional, os respondentes aparentemente apresentam o mesmo nível de habilidades mesmo estudando em modalidades de ensino diferentes. Por fim, a competência multimídia não foi pesquisada por ser necessária uma análise mais qualitativa para fazer esta avaliação sobre os alunos saberem utilizar as ferramentas multimídia.

\section{Referências Bibliográficas}

Alava, Séraphin et al. "Ciberespaço e formações abertas: rumo a novas práticas educacionais." Trad.: Fatima Murad. Porto Alegre: Artmed, 2002. 219 p.

Amiel,T.; Amaral,S.F. "Revista Brasileira de Informática na Educação". Volume 21, Número 3, 2013. 
Araújo, Julio Cesar. "Os gêneros digitais e os desafios de alfabetizar letrando." Trab. Ling. Aplic., Campinas, 46(1): 79-92, Jan./Jun. 2007.

Araújo, Fabricio O. Araújo, Gilderlanio S. Lima, Maria Cilene S. "O Letramento Digital sob a luz da Web 2.0: Experiências de um Projeto de Inclusão Digital.” Anais do Simpósio Brasileiro de Informática na Educação (SBIE), 2010.

Behar, Patricia Alejandra, Organizadora. Competências em educação a distância. Porto Alegre: Penso, 2013.

Behar, Patricia Alejandra, Bernardi, Maira, Maria, Sandra Andrea Assumpção. Educação a distância: a construção de competências docentes. II Congresso Brasileiro de Informatica na Educação, 2013.

Buzato, Marcelo El Khouri. Inclusão digital como invenção do quotidiano: um estudo de caso. Revista Brasileira de Educação v. 13 n. 38. 2008.

Letramento e inclusão: do estado-nação à era das TIC. DELTA [online]. 2009, vol.25, n.1, pp. 01-38. ISSN.

CETIC - Centro de Estudos sobre as Tecnologias da Informação e da Comunicação. "Pesquisa sobre o Uso das Tecnologias de Informação e Comunicação no Brasil." São Paulo, 20 de junho de 2013. Disponível em http://www.cetic.br. Acessado em 29 de maio de 2014.

FGV/ CPS - Fundação Getúlio Vargas - Centro de Pesquisas Sociais. "Renda e BemEstar”. Disponível em http://cps.fgv.br/node/3999. Acessado em 02 de junho de 2014.

Freitas, Maria Teresa. Letramento digital e formação de professores. Educ. rev. vol.26 no.3 Belo Horizonte Dec. 2010.

Gil, Antonio Carlos. Métodos e Técnicas de pesquisa social. 6 ed. São Paulo: Atlas 2008.

Oliveira, Sidnei. Geração Y: o nascimento de uma nova versão de líderes. São Paulo: Integrare, 2010.

Revista IHU - Revista do Instituto Humanitas Unisinos IHU, ed. 361, p. 1516, maio 2011.

Ribeiro, Ana Elisa. "Navegar sem ler, ler sem navegar e outras combinações de habilidades do leitor." Educação em Revista Belo Horizonte, v.25 n.03, 2009.

Roesch, Sylvia Maria Azevedo. Projeto de Estágio e de Pesquisa em Administração. 2 ed. São Paulo: Atlas, 1999.

Saccol, Amarolina Zanela [org.]. Metodologia de Pesquisa em administração: uma abordagem prática. São Leopoldo, RS: Ed. Unisinos, 2012. 